\title{
Variaciones villeras: nuevas demarcaciones políticas
}

PAola Cortés-RoccA

Recibido: $19 / 03 / 2016$

Aceptado: 20/04/2016

Resumen: En La virgen cabeza (2009) de Gabriela Cabezón Cámara y en La boliviana (2008) de Ricardo Strafacce, la cría de animales es un regreso paródico al modelo "agrícolo-ganadero" del siglo XIX, es decir, una consideración de lo animal como mercancía, como parte del ahora degradado circuito de producción y acumulación de capital. En ambos relatos, el escenario privilegiado es la villa y la cría de animales es la clave de una prosperidad económica provisoria. Este trabajo aborda la inscripción de lo animal en la ficción literaria posterior a la crisis del 2001 en Argentina, en tanto parodia del pasado nacional y también clave de la utopía económica y comunitaria. El animal articula la formulación de nuevos espacios -ya no totalmente nacionales ni inocentemente globales-, nuevas formas de sociabilidad y asociación comunitaria, nuevos modos de gobierno y de activismo.

Palabras claves: animalidad - villa - multitud - crisis del 2001

\begin{abstract}
In La virgen cabeza (2009) by Gabriela Cabezón Cámara and in La boliviana (2008) by Ricardo Strafacce, animal husbandry is a parodic return to the XIX century agricultural and livestock model, ie, a consideration of the animal as commodity, as part of the now degraded circuit of production and accumulation of capital. In both novels, the privileged setting is la villa (the slum) and animal husbandry is the key to a temporary economic prosperity. This paper addresses the inscription of the animal in the literary fiction post- 2001 crisis in Argentina, as a parody of the national past, but also as a key element of the economic and community utopia. The animal articulates the formulation of new spaces, new forms of sociability and community and new ways of governance and activism association.
\end{abstract}

Keywords: Animality - Slum - Multitude - 2001 crisis 


\section{Cinismo y utopía}

¿Con qué sueña la imaginación política del presente? ¿De qué materiales están hechos esos sueños? ¿Cuáles son sus motivos recurrentes, cuáles los omitidos? ¿Cuál es su gramática, cuáles sus entonaciones? Tal vez estas preguntas no sean otra cosa que un modo de interrogar la tarea misma de la práctica intelectual: la localización de lo inédito del presente, de aquello que está por articularse, de aquello que todavía no ha sistematizado su vocabulario, la exploración de aquellos grumos de divergencia que interrumpen la historia y dan lugar al surgimiento de lo nuevo.

El ocaso de la euforia por los estudios culturales -y la tarea de expandir la noción de cultura con el objetivo de incluir nuevos objetos y prácticas de la cultura popular y la masiva, de las articulaciones visuales y transformaciones técnicas- coincide, paradójicamente, con la consideración del fin o los límites de la autonomía estética o más específicamente de la tradición letrada. El horizonte de aspiraciones de la literatura, ya no está dado por la "larga tradición de las letras [sino por] otra más breve, la de las artes contemporáneas" (Laddaga, 2008: 14). Así, el objetivo central de la narrativa ya no parece ser el de producir representaciones del mundo, ni poner en escena los procedimientos verbales que marcarían la especificidad de lo literario o su peculiaridad intensidad. Se trataría más bien de construir objetos que se presentan a sí mismos como dispositivos de exhibición de fragmentos del mundo, no importa si son realidad o ficción, precisamente porque operan un vaciamiento de las categorías de autor, sentido, obra.

Marcados por el signo del nuevo milenio, habría escrituras diaspóricas -en tránsito desde una esfera a otra, interrogando la distinción misma- destinadas a fabricar presente, modos de percibir y de hablar del presente. Me interesa en particular, aquellas escrituras menos preocupadas por los modos de la convivencia -multicultural, multigenérica, multirracial-y la producción de consenso cultural y más atentas a las formas del disenso, la desigualdad y la exclusión o, lo que en términos de Rancière define la comunidad política (y la diferencia de la ética). Me detengo, entonces, en algunos aspectos de dos novelas, La virgen cabeza de Gabriela Cabezón Cámara (2009) y La boliviana, de Ricardo Strafacce (2008) en tanto objetos que exhiben y al mismo tiempo fabrican el vocabulario y los tonos con los que narrar las transformaciones de la comunidad política. 
Son relatos que toman como punto de partida uno de los efectos más visibles de la contradicción globalizadora: el flujo de capital e información y la fijación espacial de las desigualdades sociales y económicas. Al localizar en la villa, el escenario privilegiado desde el cual producir una reflexión política contemporánea, se trata de ficciones que problematizan al protagonista del discurso político: no parece ser el Estado que se sugiere ausente o en proceso de retirada, ni nociones clásicas de masa, pueblo, etc., ni siquiera parecen recuperar la figura más o menos orgánica del trabajador, el proletariado o el militante.

Son ficciones políticas que señalan no sólo la crisis de los relatos nacionales, de los discursos de la militancia de los 70s, de los espejismos del neoconservadurismo de las décadas siguientes, sino también, de las políticas identitarias más recientes. Incluso problematizan el lugar del populismo -como modelo de inteligibilidad y como de modo de acción- en la discusión contemporánea sobre el campo político latinoamericano. Son relatos que no celebran ninguna de las fábulas del neoliberalismo pero tampoco se construyen como crítica, diatriba o injuria de esos núcleos. Identifican como espacio emblemático de la globalización capitalista a la villa, a ese reducto de pobreza que lejos de ser una excepción está en el corazón mismo de la metrópoli latinoamericana. En lugar de coleccionar estampas exóticamente embellecidas de la miseria o de convertirla en el lugar de la resistencia épica o la injusticia sufriente, conceptualizan la comunidad villera como el espacio en el que decanta la discusión sobre la biopolítica y el biopoder, como la geografía desde la cual conjeturar nuevas aproximaciones a la política contemporánea.

Podríamos pensar estos textos como los verdaderos relatos cínicos de este nuevo milenio: ${ }^{1}$ actúan una aceptación perversa del estado de cosas y lo eyectan

\footnotetext{
${ }^{1}$ En "La nación. Tonos antinacionales en América Latina", Josefina Ludmer lee una serie de textos -El asco, de Horacio Castellanos Moya, La virgen de los sicarios, de Fernando Vallejo y Contra o Brasil, de Diogo Mainardi- para identificar la constitución de una voz cínica. Se trata de una voz antipatriótica que "ataca no solo a 'la nación' sino también a 'la lengua'; se funda en la fusión afectiva nación-territorio lengua; todos sufren una paralela degradación o pasaje al polo negativo" (Ludmer 165). No son relatos que simplemente degradan o negativizan algo -la idea de nación, el territorio nacional, la identificación entre territorio y lengua, etc.- sino que si lo hacen es porque identifican, capturan, exponen, extreman, es decir, ventrilocuizan -he aquí su carácter cínico-, una voz antinacional que no le es propia sino que "estaba en la realidad (y que acompañaba las privatizaciones de lo público" durante el neoliberalismo de los años noventas (Ludmer 160).
} 
hacia el futuro, acentuándolo en su aceleración. Con una construida superficialidad, se esmeran por producir utopías incluso si socarronamente postulan el movimiento irremediablemente expansivo de la periferia. Su cinismo reside en ese encogerse de hombros, en esa narración falsamente inocente del proyecto globalizador, justamente como las condiciones que harán posible una mayor expansión de la desigualdad, una precarización de las condiciones de subsistencia que no se detendrá ante las fronteras, una gran villa global.

\section{Canción animal}

En La virgen cabeza, la comunidad villera del barrio "El Poso" cría peces en un estanque construido para el desarrollo de la piscicultura comunitaria. En $\mathrm{La}$ boliviana, los habitantes del barrio de emergencia "Las ranas", subsisten gracias a la ingesta de anfibios que se reproducen en el riachuelo contaminado que bordea el barrio. En estas ficciones de comienzos del nuevo milenio, la cría de animales es un regreso burlón al siglo XIX, es decir, una consideración de lo animal como mercancía, como parte del circuito de producción y acumulación de capital -antes agropecuario, ahora pasado por agua-. Lo que se evoca también -parodia mediante- es el carácter fundacional de ese modelo agrícola-ganadero, sus vínculos con la fundación del Estado nacional y la construcción de un modelo político republicano y liberal. Los relatos del nuevo milenio pueden leerse casi como una evocación paródica de textos clásicos del siglo XIX argentino, como Administración de estancias y demás establecimientos pastoriles en la campaña de Buenos Aires, de Juan Manuel de Rosas o como Instrucción del estanciero, de José Hernández.

En aquellos textos decimonónicos, había un espacio que era al mismo tiempo, una unidad económica, política y cultural: la estancia; en estos también: la villa. En esos textos, esa geografía era además una miniatura del espacio nacional. No sólo se imaginaba el país como estancia sino que además, pese a las semejanzas -por ejemplo con la hacienda mexicana-, la estancia sustentaba el relato de la peculiaridad nacional, de aquello que marcaba la cultura de la nación con el aura de lo irrepetible. En estas novelas también la villa es, pese a sus límites y alambrados, una miniatura de la nación e incluso de la región. Las villas que propone la narrativa del nuevo milenio son, pese a sus peculiaridades nacionales, zonas donde efectivamente hay un esfuerzo -aunque sea irónico- 
por construir lo latinoamericano no tanto como rasgo común, sino como una suerte de desposesión o exclusión compartida. Si hay algo que pueda llamarse Latinoamérica, parecen decir las novelas, no se trata tanto de un continente donde todos tienen algo en común -por ejemplo una lengua o una historia en la que pueden puntuarse ciertas repeticiones-, sino de una comunidad conformada, igual que el sujeto populista, por el no tener. ${ }^{2}$

Un paisaje -la llanura, la estancia, la selva, la ciudad o la villa- es resultado de un conjunto de operaciones culturales sobre un territorio dado. El paisaje es siempre un dispositivo que articula un espacio con un modo de percibirlo y habitarlo. Por eso los paisajes son núcleos potentes en la construcción de identidades y modos de distribución de la autoridad. La estancia decimonónica produce estancieros, capataces y peones del mismo modo que la villa aloja a los villeros y a sus líderes: en el caso de la novela de Strafacce, se trata de una hermosa chica boliviana; en el de la novela de Cabezón Cámara, de una pareja conformada por Cleopatra -la travesti que habla con la virgen- y la periodista que fue a cubrir el milagro y se transformó en su amante y en una exitosa letrista de la opera cumbia que abre cada capítulo de La virgen cabeza.

El núcleo de ese dispositivo político y subjetivo que se espacializa en la estancia es la vaca, un animal que subraya, ahonda y especifica todo aquello que distingue lo animal y lo humano. En ese régimen de signos y de prácticas en el que se inscribe, la vaca es propiedad y el estanciero propietario; la vaca es pesada y apacible obediencia, el arriero, decisión y velocidad. Juan José Becerra, nos recuerda también que "las escuelas públicas incluían en sus cursos inferiores un

\footnotetext{
${ }^{2}$ El populismo - tal como lo propone la definición formal de Ernesto Laclau- no es un programa político o una forma de gobierno, sino un modo de articular ciertos contenidos ideológicos que tiene efectos estructurantes a nivel de la representación. El populismo se da en la medida en que un conjunto de prácticas político-discursivas constituyen un sujeto popular a) como agente de la historia, b) a partir de un límite interno que lo distingue y lo opone a otro agente social, y c) esa división entre el pueblo y su enemigo o su otro se funda en la constitución de una cadena de demandas insatisfechas que no tienen sentido individual sino en tanto forman parte de una cadena de equivalencias. Así, lo que constituye a ese sujeto social llamado pueblo no es una serie de rasgos comunes, ni una lucha por reivindicaciones a conseguir en el futuro, sino justamente una serie de demandas históricamente no satisfechas. La insatisfacción del pueblo, en tanto efecto global de una cadena -más allá de las peculiaridades de las demandas y las formas de la insatisfacción, es lo que lo constituye y le da unidad como sujeto colectivo.
} 
ítem llamado Composición tema la vaca" (...) ese ejercicio curricular era la primera experiencia del pequeño escolar con la escritura" (Becerra, 2007: 35). La vaca no sólo da la leche, también da letra: exhibe la escena de ingreso a la escritura, esa escena en la que el animal se vuelve un tema de la escritura y el pequeño escolar, el escribiente que ahonda la brecha que lo separa de las bestias, lo iletrado o lo bárbaro. Como toda escena escrituraria es una escena civilizatoria, es decir, un ritual de pasaje desde lo bárbaro a lo civilizado -que es, además del mundo de la escritura, el mundo de la comunidad nacional-y, al mismo tiempo, tal como ocurre con todos estos rituales de desplazamiento de un polo a otro, un modo de definir y reforzar la distinción misma entre lo civilizado y lo bárbaro.

El conjunto de diferencias que se traman alrededor de lo animal y lo humano constituyen también una suerte de modelo narrativo sobre los modos de circulación y reproducción del capital. No se trata aquí de recordar la historia de instituciones como por ejemplo la Sociedad rural -fundada en 1866 con el propósito de "velar por el patrimonio agropecuario del país" y con el lema "Cultivar el suelo es servir a la patria"- sino de percibir a la vaca como la mercancía por excelencia: es aquello que aparece por arte de magia, caído de los cielos o de la prosperidad de la tierra y que no cuenta en tanto unidad sino como parte de una serie. "Cada bestia es igual a otra que es la misma. Como si no existiera un animal, sino una idea; como si en la pampa no hubiera vacas vivas sobre la tierra sino ideas variadas de biologías y riquezas" (Becerra, 2007: 31). La vaca constituye además, el ejemplo mismo de la vida transformada "mansamente" en objeto: pese a estar dotada de una visión de 360 grados, la vaca no percibe lo que está arriba de su cabeza. Alineado a la máquina, el matarife y los martillos mecánicos del matadero, se ubican precisamente ahí, en ese punto en el que coinciden la falta de percepción bobina y el golpe donde el animal deja de ser vida para transformarse en bifes, camperas de cuero y otros objetos de venta.

En la narrativa del nuevo milenio, el pasaje de la ganadería a la piscicultura no es sólo una manera de dejar atrás un modo de producción, también se erosiona, punto por punto, el conjunto de diferencias que separaban el orden de lo animal y el orden de lo humano (la vaca vs. el estanciero y los peones, la mercancía vs. el capital y el trabajo). Y por lo tanto, impulsa una transformación en la economía subjetiva y política que se despliega en cada espacio, así como en los modos 
de formación de colectividades y de relatos nacionales. En La virgen cabeza, si la comunidad elige criar carpas es precisamente porque, al igual que los villeros, estos peces no tienen un régimen de alimentación ligado a la propiedad de la tierra: "cualquier porquería comen, lo que comíamos nosotros le tirábamos, pancho, choripán y se lo comían con chimichurri y todo" (Cabezón Cámara, 2009: 67).

Así, la ficción conjetura un mundo en el que las diferencias y las jerarquías le ceden su lugar a nuevas formas de asociación horizontal, formas que evocan las cadenas de trueque o fábricas recuperadas por cooperativas obreras que suceden a la crisis del 2001 y que, en la novela, son incluso el motivo de una provisoria prosperidad económica. Se dice de los peces carpas casi lo mismo que se dice de las vacas: están ahí y se reproducen. "Todo se reproducía, parecía Ámsterdam El Poso entre tanta agua y tanta flor y tanto humo de marihuana, pero nada se multiplicaba como las carpas en nuestro mundo (...) Nosotros cogíamos también, claro, pero no nos reproducíamos, pasó lo propio de la abundancia: nos dedicamos casi exclusivamente al placer. Y a comer carpa en guiso, con chimichurri, en chop suey, en puchero," explica la narradora (Cabezón Cámara, 2009: 81). Pero en este caso, la reproducción animal y la abundancia económica no están ligadas a características "esenciales" del paisaje -como la vaca a la tierra fértil de la estancia-, sino que duplica ciertas formas de asociación subjetiva propiciadas por el espacio de la villa. La reproducción animal que conduce a la abundancia y al placer dialoga con la asociación de albañiles, putas, travestis, niños, sirvientas, periodistas, chicas de la facultad, el chino del supermercado, un ex agente del servicio de inteligencia y Susana Giménez - una estrella televisiva que vieja y paralítica que vuelve a caminar gracias a un milagro que involucra a la virgen. La reproducción animal redobla la mescolanza entre el discurso militante y religioso, el de las asociación civil, los partidos políticos, la televisión; el menjunje de letras de cumbia y referencias a los mitos clásicos que se evocan con insistencia.

Las carpas, que se eligen porque comen cualquier porquería como sus criadores y que abren el espacio a la abundancia y al placer, se multiplican finalmente porque "en el barroco miserable de la villa, cada cosa siempre arriba, abajo, adentro y al costado de otra, todo era posible. Y eventualmente, divertido: de tanta 
superposición, todo cogía con todo" (Cabezón Cámara, 2009: 111, el énfasis es mío). Si todo era posible, si hay espacio para imaginar nuevas utopías políticas, es porque el espacio de la villa da lugar a la configuración de -en palabras de la novela- "una alegre multitud": de una superposición de sujetos que no son idénticos, que siguen siendo diferentes entre sí y que no por eso dejan de estar juntos. La noción que Hartdt y Negri definen como elemento clave de la política en la era del imperio no se evoca aquí sólo para identificar un colectivo que preserva en sí la multiplicidad -a diferencia de otras categorías colectivas como pueblo, masa, muchedumbre, etc. que operan a partir de la unificación-, sino también para señalar una transformación histórica que se da en los discursos que, desde Latinoamérica misma, le dan legibilidad a lo social. ${ }^{3}$ La virgen cabeza evoca la multitud del siglo XIX, ese colectivo que resulta del hacinamiento, ese foco de infecciones sociales que la bio-medicina legal -el higienismo, la criminologíadebe aislar y sanear. La ficción del nuevo siglo evoca la multitud que desveló a Ramos Mejía y José Ingenieros en Argentina -así como a Miguel Macedo y Julio Guerrero en México, a Fernando Ortiz en Cuba, Octavio Beche en Costa Rica, Clovis Bevilacqua y Afraino Peixoto en Brazil- para inmediatamente leerla en clave de la prestigiosa tradición estética del barroco. Así, la multitud, una entidad que amenaza el orden social en términos de peligro, según el positivismo del siglo XIX, se vuelve collage de temporalidades y universos distintos cuando es leída en la clave del barroco latinoamericano. Del mismo modo, "la promiscuidad de la pobreza", una frase que no aparece en la novela justamente porque

\footnotetext{
${ }^{3}$ La multitud es justamente aquello que permanece plural y múltiple, que no reduce las diferencias con el objetivo de conformar una identidad, como sí lo hacen nociones como la de pueblo, masa, muchedumbre, etc. A diferencia de estas otras categorías colectivas, la multitud es un tipo de sujeto social que no puede ser pensado como pasivo, no es resultado de una oposición entre la razón soberana y el cuerpo de los súbditos, la multitud es la carnalidad de lo viviente dándose sus propias leyes. Sin embargo, lo radicalmente novedoso del concepto de multitud no es su capacidad de conceptualización de una nueva realidad social, sino justamente su carácter programático: "political action aimed at transformation and liberation today can only be conducted on the basis of the multitude", dicen Hardt y Negri (99) en la frase que abre el capítulo titulado "Multitude". La imaginación literaria del nuevo milenio, parece entender perfectamente esta última dimensión: no se trata de definir ni describir la formación de nuevas asociaciones, no se trata de evaluarlas y de considerar su valor en diferentes contextos. Se trata antes que nada de hacer multitud, de proponer modos de asociación que no son otra cosa que modos de la acción.
} 
pertenece al vocabulario criminológico, se reinscribe en la retórica de las luchas sexuales y políticas de los años sesentas y setentas y así adquiere su carácter utópico: un espacio en el que "todo cogía con todo" es justamente un espacio en el que "todo era posible" y "eventualmente divertido", nos dice la novela. ${ }^{4}$

La imaginación política de La virgen cabeza, desestima una serie de diferencias -entre cuerpo y escritura, subsistencia y agencia, animales y humanos, ciencia y estética, o finalmente vida calificada y vida en estado puro- en tanto diferencias ontológicas para interrogar en cambio, "not the metaphysical mystery of conjunction, but rather the practical and political mystery of separation" (Agamben, 2004: 16). ${ }^{5}$ La multitud funciona entonces, no sólo como una matriz de percepción de lo social -que transforma un dispositivo de control social en una retórica de la resistencia-, sino también como una forma de articulación de lo político -que mantiene cierta distancia crítica con las formas históricas de la delegación política, formas que descansan en mecanismos de representación y sustitución por ejemplo, ya sea entre los representantes y la masa electoral, el líder y el pueblo, etc.- y un modo de enfrentar la desigualdad social. Se trata de una utopía que no se coloca en un futuro posible ni se instala en el presente del

\footnotetext{
${ }^{4}$ El gesto cínico estaría hecho justamente de esta liviandad que despreocupadamente altera el modo de percibir y narrar ciertos fenómenos sociales. Por ejemplo, para la teología tomista, el paraíso -el del Génesis pero también el vendrá luego del juicio final y con la resurrección de los cuerpos-, es un lugar en el que toda necesidad corporal se suprime. Tal es así que Giorgio Agamben se detiene allí para analizar el modo en que la retórica cristiana homologa el contacto con la divinidad con el momento mismo de negación de lo animal, el momento de retroceso de la pura vida o de la mera corporalidad (ver especialmente "Physiology of the Blessed"). En la lengua de literaria de la novela, la religiosidad es el punto de mezcla por excelencia entre lo humano y lo animal. Una "versión" latinoamericana y popular del relato bíblico da, en la novela, origen a la piscicultura -Cleopatra, la travesti que habla con la virgen, explica que "la santa madre le dijo que deben ser pescadores, como los apóstoles"- y el conjunto de figuras que la novela retoma identifica el espacio de la utopía política y de la recompensa religiosa. La villa aloja a la comunidad de pescadores, es el espacio de la multiplicación y de la abundancia, un lugar que parece homologarse, en el lenguaje de la religiosidad popular y mediática de la novela, con el paraíso.

${ }^{5}$ La pregunta por la formulación de estas oposiciones o por el modo en que estas oposiciones constituyen la humanidad del sujeto humano, es para Agamben, "not just one question among many discussed by philosophers and theologians, scientists and politicians, but rather a fundamental metaphysical-political operation in which alone something like 'man' can be decided upon and produced" (Agamben 21).
} 
relato, sino que se incluye en el flujo de una lucha continua. En la historia de la virgen cabeza, cuando la abundancia y el barroco divertido se terminan, cuando la villa es desalojada, con topadoras, policías y los muertos que los nuevos emprendimientos urbanísticos siempre traen, la narradora recuerda ese "tiempo de bocas abiertas: las de las carpas que hacían 'o' y trataban de tragar todo lo que se les cruzaba; su forma de estar en el mundo era tratar de comérselo (...). Y el mundo se las comía a ellas: ahí estábamos nosotros con el corazón contento de carpas y cagándonos de risa, sin pensar demasiado en que también nos devorarían: desde sus helicópteros, los dueños de las cosas nos verían igual que veíamos nosotros a las carpas" (Cabezón Cámara, 2009: 95).

Lo que distingue la vida calificada y la pura vida no está antes sino después de la economía que distribuye cuerpos, mercancías y capitales; no es una diferencia ontológica, sino un efecto práctico y político del orden de la propiedad y de la clase. La novela erosiona la noción de sujeto-como efecto de la diferencia entre vida calificada y mera vida- en tanto fundamento de un orden político para proponer que la diferencia entre los animales, los villeros y los hombres de los helicópteros es un efecto práctico y político del orden de la propiedad, un efecto que se narra como proceso de representación -como un modo de ver y ser visto por el otro-. El que devora, no es, sino que provisoriamente ocupa el lugar de lo humano. Es el dueño de las cosas (de las vacas, de las carpas, de aquellos a los que explota). El otro, el que no es dueño de nada, no es dueño ni siquiera de su propio cuerpo. Ese último ocupa siempre el lugar del animal que, como bien sabemos, finalmente va a parar al matadero.

Se trataría entonces de efectos de humanización y animalización, que la novela reacomoda imaginando nuevas asociaciones y nuevas configuraciones subjetivas y apostando por una lengua que se inscribe en la tradición de César Aira y se acelera lanzándose hacia al futuro. Cuando la abundancia y el barroco divertido se terminan, cuando la villa es desalojada, nuestras heroínas, luchadoras incansables, levantan lo que queda, lo meten en una bolsa del supermercado Coto y se lo llevan a otra parte. Se van a Miami, a ese lugar que la novela cínicamente identifica como el corazón mismo de Latinoamérica o la villa global. Lo que queda, es un significante vacío que se llena de muchas cosas y que funcionó como nexo de la comunidad: es la cabeza de la virgen, que es rubia como Eva 
Perón y como Susana Giménez, la diva de la televisión argentina. Incluso como ruina, la cabeza de la virgen sigue abriendo el espectro de la identificaciones subjetivas porque, según la travesti, siempre fue una mujer valiente porque "no sabés lo que era pretender hablar siendo una madre judía soltera de quince años" cuando "ni siquiera habían inventado las idishe mame, (...) un quilombo era, les parecía más tremenda de lo que les parezco yo ahora" (Cabezón Cámara, 2009: 92).

\section{Si Evita viviera...}

La narrativa de la estancia decimonónica identificaba un quiebre temporal: antes estaba el mundo colonial en retirada, ahora y hacia adelante, el moderno capitalismo agrícola-ganadero. En estos relatos del nuevo milenio, ese momento de quiebre se localiza a mediados de los años cuarenta, cuando ciertos sujetos, que se contabilizan -igual que el ganado- como "cabezas" y que ponen "las patas en la fuente" de la plaza de Mayo, ocupan la escena política. Es el momento de la consolidación de la biopolítica en Argentina, el momento en el que el sujeto político por excelencia ya no es el ciudadano en tanto vida calificada, sino la población en tanto conjunto de cuerpos que anudan necesidades e instintos. ${ }^{6}$ Es la época de la patria peronista con su retórica del cuerpo, la salud, la reproducción, el deporte, y el conjunto de relatos y mecanismos destinados a la administración de lo viviente.

La novela de Ricardo Strafacce, La Boliviana, también se desarrolla en una villa. El Barrio de los Sapos es un espacio excluido de cualquier política de administración de los cuerpos; allí no llega el Estado, no hay escolarización, ni ley, ni salud. Por supuesto -y aquí reside la utopía cínica de la novela-, "en el barrio no había autoridad policial ni puesto sanitario, lo cual no constituía ningún problema porque, por una parte casi nadie delinquía (y los que lo hacían se iban a

\footnotetext{
${ }^{6}$ Tal vez ningún texto identifica mejor que "La fiesta del monstruo", de Borges y Bioy Casares, la coincidencia entre el conjunto de transformaciones que se da en la escena política y en el lenguaje para narrar lo político en Argentina. "La fiesta" es justamente eso: el intento de definir al peronismo no sólo como el aluvión zoológico que invade la esfera de lo público, sino también y sobre todo como el sedimento animal que se deposita sobre la lengua de la nación.
} 
practicar sus fechorías a otros sitios), y, por otra, los habitantes del Barrio de los Sapos nunca se enfermaban" (Strafacce, 2008: 11). Los habitantes no se enferman porque viven a orillas de un riachuelo contaminado y su única dieta la constituye los sapos radiactivos que nadan en esas aguas podridas.

Lo que ingresa a la villa ya no es la administración del estado sino el Dr. Clavel Karrufa, "un famacotraficante con pedido de captura en cincuenta países, pero al mismo tiempo, asesor free-lance de los más importantes laboratorios del mundo" (16) y "una media docena de investigadores del Conicet pasados a las filas del farmacotraficante" (17). Simplemente invaden el barrio porque advierten que "a partir del contacto con toda clase de porquerías, los sapos se habían hecho inmunes a todo, inmunidad que trasmitían a quienes comían de su carne magra y de gusto ácido. Aislando los anticuerpos de los sapos, pensaba el científico, podían extraerse vacunas, pastillas y tisanas contra todos los males de este mundo" (16). La prosperidad económica que experimenta el barrio no es aquí resultado de un emprendimiento colectivo -como en la novela de Cabezón Cámara-, sino efecto del libre juego de las corporaciones: el doctor Karrufa paga "un peso el sapo y cincuenta pesos más por día fijos a todos los que quisieran trabajar en el carneado" y así, al mismo tiempo que da empleo a los villeros, enferma "a toda la población al cambiarle al dieta de sapo por los manjares de rotisería" (27).

Ambas novelas localizan el espacio de político como un espacio de desamparo, como el hueco que deja un Estado en retirada. En ese lugar, una serie de cuerpos a la intemperie, traman nuevas alianzas, nuevas formas de intervención y de asociación. Hay cierta graciosa melancolía en La virgen cabeza, en la sugerencia de su título -la virgen de los llamados "cabezas", la virgen popular, la virgen peronista-, en ese pasado perdido -si Evita viviera... seríamos peronistas, dice una de las protagonistas-, y en los intentos por explorar las formas afectivas del liderazgo y la delegación política. La Boliviana elige una dirección distinta y proyecta el futuro como un peronismo retro.

La protagonista del relato es María Luján Murena, una mujer nacida en Bolivia que vive junto con su marido en el Barrio de los Sapos. Es ella, la que moviliza a la comunidad para expulsar a los invasores. Gracias a su belleza, consigue que un soldado de un cuartel cercano le preste un tanque. López, un 
compañero de trabajo de su marido, persuade a los dirigentes de la Central General del Trabajo para que se involucre en el asunto. Otro obrero, de apellido Díaz, "aburrido del besamanos al que recurrió su amigo" sale a recorrer los barrios y logra reclutar otros veinte hombres, "todos militantes, todos clasistas y combativos como él" (35). La operación es un éxito y la articulación entre ejército, sindicalismo y bases obreras -elementos centrales para la construcción de hegemonía a partir de la segunda mitad del siglo XX-se vuelve a repetir, ahora con disparatada rapidez y concordia.

La novela se cierra con una humorada sobre la suspensión de un relato comunitario construido sobre los límites nacionales que son, simultáneamente, requisito para el acceso a lugares dentro del aparato de representación política. El relato concluye parodiando también la integración regional como un espacio de apertura a nuevas formas de viejos sistemas coloniales. Las habilidades de la protagonista María Luján para proteger a la comunidad barrial se trasladan con asombrosa inmediatez - que no se explica en la novela pero que responde perfectamente a la velocidad de las tecnologías de la información simultánea-, al plano nacional. Atrás quedó la época en la que la lógica política hacía coincidir Estado, Nación y territorio, así que todos quieren que María Luján sea presidenta. Como esto no es posible, ya que la protagonista del relato nació en Bolivia, la opinión pública recurre al pasado común en el que ambos países formaban parte del mismo virreinato. Esta evocación de un territorio y una identidad que antecede al trazado de las fronteras nacionales - un gesto que está en el origen, por ejemplo, de la cultura chicana-, tiene un carácter puramente instrumental, y por lo tanto, satírico. Como Bolivia no acepta ese pasado común, se le sugiere anexarse a Argentina. Cuando esta propuesta es rechazada, la solución final es "IN-VASION". María Luján, que es una mujer sensata, renuncia a ser la primera presidenta argentina y así se mantiene la paz en Latinoamérica.

Sin la obligación de sistematizar una hermenéutica de lo social, la literatura capta jirones de lenguaje en los que resuena la pregunta por el funcionamiento de la crisis de soberanía y de inteligibilidad -cuál es el vocabulario, cuál es el abordaje con el que leer e intervenir en la escena política-. Y hace de ese lenguaje en ebullición, la materia misma con la que tramar el relato. Estas ficciones exploran la razón sentimental de lo político, con sus mitos de origen y sus hori- 
zontes de prosperidad futura. De hecho, pueden leerse como versiones complementarias y divergentes de las lógicas de constitución y representación del sujeto popular. ${ }^{7}$ En ambos relatos, el liderazgo surge del pueblo mismo: la travesti de $\mathrm{La}$ virgen cabeza o la boliviana del relato de Strafacce parecen revelar que no hay delegación populista, sin una prehistoria de ese momento en el que el líder también era parte de ese nosotros insatisfecho y, por lo tanto, efectivamente intercambiable por cualquier otro integrante del pueblo al que representa. El sujeto colectivo, el motor de la historia, está amenazado por la dispersión en La virgende hecho, la multitud parece ser justamente un modo programático de reformular la uniformidad de la categoría de pueblo-. La Boliviana, en cambio, adscribe con seriedad a la tradición nacional y popular sólo que la deslocaliza burlándose de las fronteras nacionales y regionales. Ambos relatos distinguen cuidadosamente liderazgo y representación para desplegar los mecanismos de una representación fallida, que toma la forma de una presidenta extranjera o de una líder religiosa y política cuyo marco de referencia es su experiencia como trabajadora sexual y sus saberes sobre el universo de las celebrities locales.

Los relatos cínicos del nuevo milenio se constituyen como dispositivos para percibir lo real; exploran los tonos del humor, la burla, la obscenidad y la injuria, para amplificar las resonancias del vocabulario político. No nos ofrecen alguna versión de la retirada de lo común o del desencanto finisecular, sino que muy por el contrario, se presentan como fragmentos de una nueva imaginación política: conjeturan nuevas formas de sociabilidad y asociación comunitaria, figuran nuevos modos de activismo, imaginan nuevas utopías políticas.

\footnotetext{
${ }^{7}$ Para Laclau, el populismo estaría en el corazón mismo de lo político, y por lo tanto no cabría preguntarse si un movimiento o una ideología es populista, sino en qué medida es populista. Un discurso será más populista en la medida en que sus contenidos estén más articulados por la lógica de la equivalencia. Es decir, será más populista cuanto más capacidad posea para construir equivalencias entre reivindicaciones específicas, para olvidar sus peculiaridades y hundirlas en el conglomerado de reivindicaciones del sujeto popular.
} 


\section{Bibliografía}

Agamben, Giorgio (2004). The Open: man and animal. Stanford: Stanford University Press.

Becerra, Juan José (2007). La vaca. Viaje a la pampa carnívora. Buenos Aires: Arty Latino.

Cabezón Cámara, Gabriela (2009). La virgen cabeza. Buenos Aires: Eterna Cadencia. Esposito, Roberto (2002). Communitas. Origen y destino de la comunidad. Buenos Aires: Amorrortu.

Hardt, Michael y Antonio Negri (2004). Multitude. War and democracy in the Age of Empire. New York: Penguin.

Laclau, Ernesto (2005). La razón populista. Buenos Aires: Fondo de Cultura económica.

Laddaga, Reinaldo (2008). Espectáculos de realidad. Ensayo sobre la narrativa latinoamericana de las últimas dos décadas. Buenos Aires: Beatriz Viterbo.

Ludmer, Josefina (2001). Aquí América latina. Una especulación. Buenos Aires: Eterna cadencia.

Rancière, Jacques (2006). El viraje ético de la estética y la politica. Santiago de Chile: Palinodia.

Strafacce, Ricardo (2008). La Boliviana. Buenos Aires: Mansalva. 